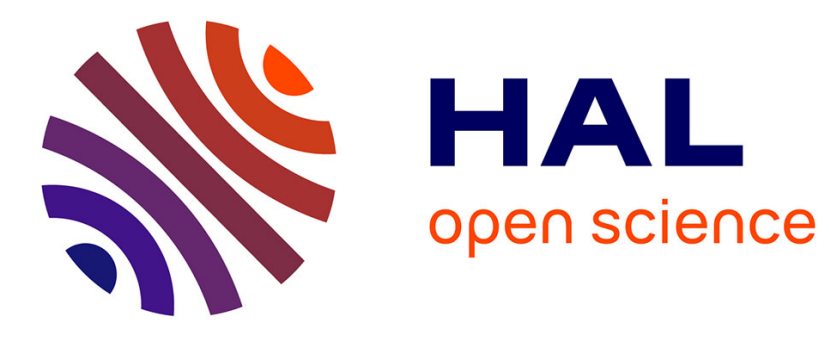

\title{
Strategic Enterprise Architectures
}

Evellin Cardoso, John Mylopoulos, Alejandro Mate, Juan Trujillo

\section{To cite this version:}

Evellin Cardoso, John Mylopoulos, Alejandro Mate, Juan Trujillo. Strategic Enterprise Architectures. 9th IFIP Working Conference on The Practice of Enterprise Modeling (PoEM), Nov 2016, Skövde, Sweden. pp.57-71, 10.1007/978-3-319-48393-1_5 . hal-01653508

\section{HAL Id: hal-01653508 https://hal.inria.fr/hal-01653508}

Submitted on 1 Dec 2017

HAL is a multi-disciplinary open access archive for the deposit and dissemination of scientific research documents, whether they are published or not. The documents may come from teaching and research institutions in France or abroad, or from public or private research centers.
L'archive ouverte pluridisciplinaire HAL, est destinée au dépôt et à la diffusion de documents scientifiques de niveau recherche, publiés ou non, émanant des établissements d'enseignement et de recherche français ou étrangers, des laboratoires publics ou privés.

\section{(c)(1)}

Distributed under a Creative Commons Attribution| 4.0 International License 


\title{
Strategic Enterprise Architectures
}

\author{
Evellin Cardoso $^{1}$, John Mylopoulos $^{1}$, Alejandro Mate ${ }^{1,2}$, Juan Trujillo ${ }^{2}$ \\ 1 University of Trento, Italy \\ \{evellin.souzacardoso, john.mylopoulos\}@unitn.it \\ 2 University of Alicante, Spain \\ \{amate, jtrujillo\}@dlsi.ua.es
}

\begin{abstract}
Enterprise models are useful managerial tools for decision making and control, supporting the planning and design of enterprise strategic objectives as well as day-to-day operations. Although much research on the topic has been carried out since the $80 \mathrm{~s}$, most approaches offer rudimentary support for the representation of goal-related concepts, focusing either on the representation of strategic or operational goals, lacking a comprehensive ontology for goals. In contrast, this paper is interested in: (a) delineating differences between various shades of goals (mission, vision, strategic, tactical and operational goals) and operations, (b) proposing a hierarchical architecture for strategic enterprise models that includes goals and the operations/processes through which they are operationalized and (c) offering methodological guidelines on how to elaborate such models.
\end{abstract}

\section{Introduction}

Enterprise models are useful managerial tools for decision making and control. They can support the design of an enterprise given its strategic objectives, its long term planning and evolution, as well as its day-to-day operations. Surprisingly, although much research on the topic has been carried out since the 80s, most approaches offer rudimentary support for the representation of goal-related concepts. For example, ArchiMate [1] ignores the existence of operational goals, while Business Process Management (BPM) proposals [10,14, 12, 9] link operational goals to processes or connect short-term goals to operations, ignoring the existence of long-term, strategic goals.

We are interested in strategic enterprise models that capture strategic and tactical objectives and the processes through which they are realized. Such models are grounded on ontologies of goals of various shades (missions, visions, strategic, tactical, and operational), as well as ontologies of processes and operations. These models can be used both for strategic analysis and planning, as well as business analytics and monitoring. The research baseline for our work is the Business Intelligence Model (a.k.a BIM) [6] and the Business Motivation Model (BMM), an OMG standard [5]. BMM offers a rich vocabulary of concepts for modeling enterprises but lacks in formal rigor. BIM offers a core ontology of strategic enterprise concepts founded on the notions of goal and situation to define a formal framework for strategic enterprise models. 
The main objective of this paper is to improve on BIM by introducing other strategic concepts. In particular, the contributions of this paper can be stated as follows: we delineate the differences in semantics and usage of different shades of goals found in BMM (distinguishing among strategic, tactical and operational goals, mission and vision) and also offer distinctions between the concepts of operation vs. process. Further, we propose a hierarchical architecture for strategic enterprise models that includes goals and the operations/processes through which they are operationalized and finally, we offer methodological guidelines on how to elaborate such models and when should each be used in enterprise modeling.

Our StrategIc ENterprise Architecture (SIENA) modeling framework consists of two views, namely, a Goal and an Operation View. Within the Goal View, our framework distinguishes among three layers of abstraction Strategic, Tactical and Operational, whereas the Operation View depicts the set of operations and processes, i.e., the enterprise process architecture. Further, given that strategic processes may deal with a number of aspects of strategic nature and may vary according to the type and size of an enterprise, we provide methodological guidelines on how to deal with such variability in the elaboration of an enterprise's strategic models. By proposing a richer ontology of goals/operations, we lay the foundations for future reasoning capabilities, but leave the specifics to future work.

This paper is structured as follows: Section 2 provides the research baseline for our work that includes conceptualization extracted from Management Sciences and the BIM and BMM frameworks extracted from Conceptual Modeling. Section 3 describes different types of goals and operations proposed by our modeling framework, whereas Section 4 provides methodological guidelines on how to elaborate them. Section 5 contrasts our framework with related work and Section 6 summarizes the discussion and outlines future work.

\section{Baseline}

Organizations distinguish three levels of decision-making, Strategic, Tactical and Operational [17]. Inside each level of abstraction, managers have to specify a number of strategic, tactical and operational goals that focus on different enterprise concerns and must be achieved within distinct time frames.

Mission $[\mathbf{1 9}, \mathbf{7}, \mathbf{2}]$. A formal expression of an organization's purpose, i.e., the reason why the organization exists. An example of mission is "Manufacture both standard and metal products" [2].

Vision [19, 7]. Comprises a description of a desired future state of the company, meant to close the gap between the current reality and a potential future. An example of vision could be: "To be the market leader of standard and custom metal products in the machine tool industry" [2].

Strategic Goal [19]. Represents concrete outcomes or status to be achieved to measure if mission are being achieved $[7,17]$. They are directional as they guide the strategy towards achieving the organization's mission $[19,7]$. Further, strate- 
gic goals are statements about external and internal company's conditions that reflects company's strategy to succeed on business [17]. Examples of strategic goals are "Improve market share from $15 \%$ to $20 \%$ over the next three years" and "Increase gross margin on current sales" [2].

Tactical Level. Involves the planning of the actual steps required to implement such strategy $[17,18]$.

Tactical Goals (or Objectives) $[2,18]$. Define the outcomes to be achieved by major divisions and departments in the context of strategic goals. Commonly, Strategic goals can be either segmented into tactical goals that specify responsibilities of functional areas (Finance, Production and Marketing)(e.g., "Manufacture 1200000 products at average cost of $\$ 19 "$ from Operations [2]) or can define tactics for its corresponding Strategic Goal. In [19], the Border Inc.'s Tactical Goal "Open 20 new stores by the end of the planning period" specifies a tactics for the "Borders will be the leading retail distribution outlet of books in the US" Strategic Goal.

Operational Level. Concerns the planning and management of daily operations responsible for delivering products and services on behalf of the company [17]. Operations implement the tactical initiatives that are elaborated for supporting organization's strategy. Such tactical initiatives are then scheduled and eventually emerge as the set of organization's operation specifications [15].

Operational Goals $[\mathbf{1 7}, \mathbf{2}]$. Consists of quantitative and measurable results expected from departments, work groups and individuals within the organization. Most of approaches $[17,2]$ mention that both tactical and operational goals should be achieved by departments. Further analysis also reveals that both types of goals can be scheduled (e.g. "Resolve employee grievances within 3 working days" and "Respond to employee grievances within 24h"). As tactical and operational goals in Management literature present similar conceptual characteristics, it is also not clear how the achievement of operational goals entails the achievement of tactical goals. Finally, there is also a lack of clear connection of operational goals with their respective operations and the activities that compose such operations.

\subsection{Goal and Operation Modeling in Conceptual Modeling}

The Business Intelligence Model (BIM) [6] enterprise modeling approach links the business-level representation of an enterprise with the data stemmed from databases and data warehouses. In BIM, a goal represents an objective of a business which captures strategic enterprise's concerns, such as "Increase sales". Goals may be related by either refinement of influence relationships. In a refinement relation, goals are decomposed into a finer-grained structure by means of AND/OR relationships, with an AND decomposition supporting a goal to be decomposed in a series of sub-goals and an OR decomposition allowing analysts to model alternative ways of achieving a goal. Influence relationships among goals specify how the satisfaction/denial of one goal implies the (partial) satisfaction/denial of another goal. Influence strengths are modeled using qualitative 
values: + (weak positive $),++($ strong positive $),-($ weak negative $)$ and - (strong negative).

Goal models may be enriched with domain assumptions, processes and situations. Domain assumptions indicate properties that are assumed to be true for some goal to be achieved. For example, "High demand" must be true for the "Increase Sales" goal to be satisfied and if such assumption is false, then its associated goal is not satisfied. Processes can be associated with a particular goal via an "achieves" relation to denote that this process is intended to achieve the goal. Besides domain assumptions and processes, managers are usually interested in foreseeing other aspects that influence the fulfillment strategic goals during enterprise planning. In that respect, SWOT analysis [19] consists of a useful tool to identify internal and external factors that may impact positively or negatively the achievement of strategic goals. SWOT stands for Strengths (internal and favorable factors), Weaknesses (internal and unfavorable factors), Opportunities (external and favorable factors) and Threats (external and unfavorable factors). BIM proposes to model SWOT factors in terms of the concept of situation. A situation characterizes a state of affairs (state of the world) in terms of the entities that exist in that state, their properties and interrelations. Favorable situations are represented via positive influence links on goals, whereas unfavorable situations are represented via negative influence links.

The Business Motivation Model (BMM) [5] is a specification adopted by OMG for structuring the development, communication and management of business plans in enterprises. Although the importance of BMM justifies its inclusion here (Table 1), we omit a detailed description of its concepts due to space constraints, directing the interested reader to the specification in [5].

An interpretation of the semantics of definitions and examples of each concept found on Management and Conceptual modeling literatures allowed us to find overlaps and gaps in the conceptualization provided by the three aforementioned proposals of our Baseline (Section 2). Table 1 summarizes this discussion by depicting the three areas and their respective correspondences among concepts. Such overlaps and gaps have been used as input in our framework to promote a consistent integration of all concepts in the fourth column of Table 1.

\begin{tabular}{|c|c|c|l|}
\hline Manag. Sciences & BIM & BMM & SIENA framework \\
\hline Mission, Vision & - & Mission, Vision & Mission, Vision \\
\hline Strategic Goal & \multirow{3}{*}{ Goal } & Goal & Strategic Goal \\
\cline { 1 - 2 } & & $\begin{array}{c}\text { Objective, } \\
\text { Tactical Goal }\end{array}$ & Tactical Goal \\
\cline { 4 - 5 } & & - & Operational Goal \\
\hline Operational Goal & & - & $\begin{array}{l}\text { Goal Refinements and } \\
\text { Influences }\end{array}$ \\
\hline- & $\begin{array}{c}\text { Goal Refinements } \\
\text { and Influences }\end{array}$ & - & Operation \\
\hline Operation & Process & - & Business Process \\
\hline- & - & - & Domain Assumption \\
\hline- & Domain Assumption & Situation & Situation \\
\hline- & Situencers & Siturion \\
\hline
\end{tabular}

Table 1: Summary of Concepts from Literature together with Concepts from Our Framework 


\section{The Strategic Enterprise Architecture (SIENA) Modeling Framework}

\subsection{Goal View}

This section introduces the goal-related concepts of our framework following the same three-layered distinction proposed by Management Sciences (i.e., Strategic, Tactical and Operational Layers). Within our Strategic Layer, we use the concepts of Mission, Vision and Strategic Goals as can be seen at Table 1. Strategic Goals present key characteristics in Management that we consolidate as follows:

Strategic Goals. Represent goals that specify concrete outcomes that must be achieved to measure the achievement of mission, reflecting the organization's strategy to achieve success in business. Strategic goals are global to the overall organization as the entire organization is responsible for their achievement.

As Strategic Goals are global to the entire organization, they represent the problem space of a given enterprise, defining the space of all alternatives goals that can be implemented by enterprise. To precisely characterize such variability and unambiguously characterize Strategic Goals, our framework introduces the distinguishing feature of refinement dimensions. Refinement dimensions correspond to different properties along which goals can be characterized, for example, location, time or product types properties. To exemplify the use of refinement dimensions, consider the "Increase sales by $2 \%$ over 3 years" goal in Figure 1. This parent goal defines the space of all possible locations (countries, in this example) in which the company operates. Therefore, this parent goal can be refined into the following sub-goals: "Increase sales in Italy by $2 \%$ over 3 years", "Increase sales in Germany by $2 \%$ over 3 years" and "Increase sales in NL by $2 \%$ over 3 years". Another refinement of the same parent goal across time (within the year granularity) is also depicted in Figure 1, yielding the "Increase sales by $2 \%$ over 1st year", "Increase sales by $2 \%$ over 2 nd year" and "Increase sales by $2 \%$ over 3rd year" sub-goals.

As Strategic Goals define the space of all possible alternatives, they can be only AND-decomposed, but not OR-decomposed. Positive and negative contributions among Strategic Goals may be used to depict how they influence each other inside the Strategic Layer.

Within the Tactical Layer, Management literature (Section 2) commonly specifies tactical goals either as responsibilities of functional areas or tactics to achieve strategic goals. We consolidate both views in our definition of Tactical Goals as follows:

Tactical Goals. Represent goals that specify particular ways for fulfilling Strategic Goals with the available resources and capabilities of the company. Tactical Goals have no dimensions, but rather depict particular solutions ("tactics") for each point of the refinement dimension in order to fulfill a Strategic Goal. Alternatively, they can also be interpreted as responsibilities to be achieved by specific functional areas (marketing, operations, finance and human resources management) to accomplish their specific part of the organization's strategy. 


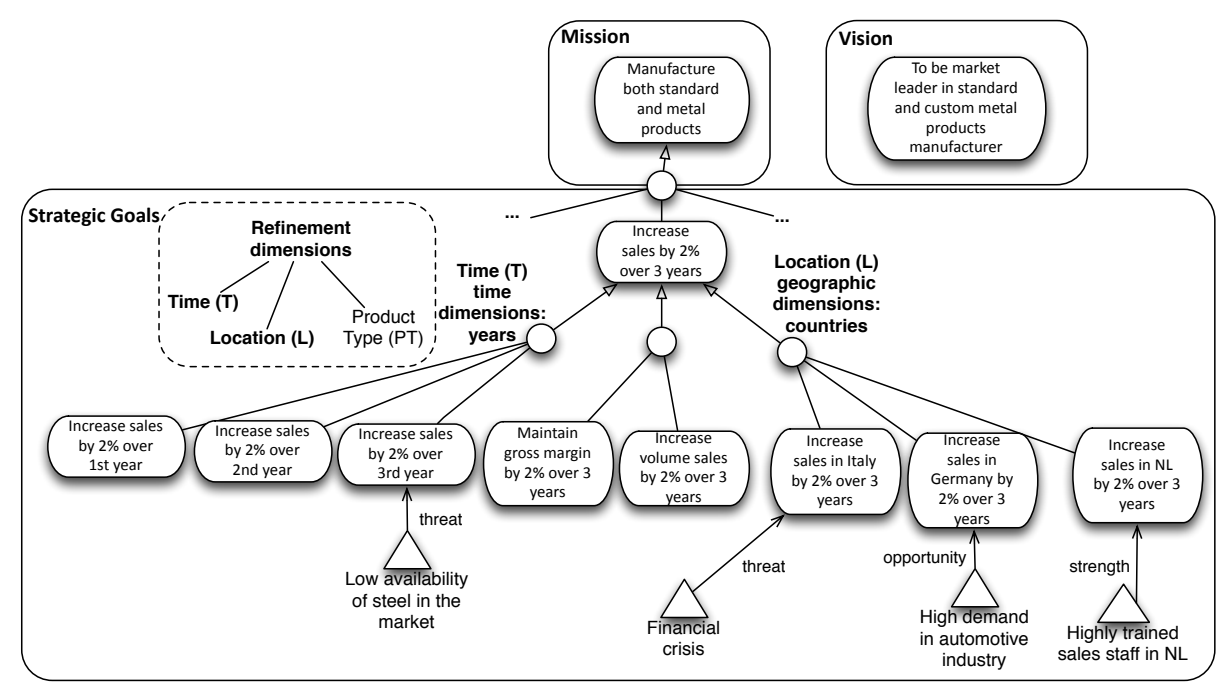

Fig. 1. Strategic Goal Hierarchy

In order to exemplify this discussion, we use the refinement of "Increase sales by $2 \%$ over 3 years" Strategic Goal across the location dimension (depicted in Figure 2). For one of the points of the location dimension (Italy) represented by the Strategic sub-goals ("Increase sales in Italy by $2 \%$ over 3 years"), there are two alternative tactics for increasing sales, i.e., promotions ("Increase sales in Italy by $2 \%$ over 3 years through promotions") or create new sales channel ("Increase sales in Italy by $2 \%$ over 3 years by opening new sales channels" Tactical Goal). For other point of the location dimension (NL), training sales people corresponds to a tactics for increasing sales ("Increase sales in NL by $2 \%$ over 3 years by training sales staff" Tactical Goal). Concerning the relation of Strategic and Tactical Goals, it said that Tactical goals implement Strategic Goals. In the example, it is said that promotions ("Increase sales in Italy by $2 \%$ over 3 years through promotions") is the tactics that implements the increase of sales ("Increase sales in Italy by $2 \%$ over 3 years"). Further, Tactical Goals may be structurally refined into sub-goals by means of AND-relationships and several alternative Tactical Goals may be also represented by means of OR-relationships. Finally, they can be also related by positive and negative contributions that depict how Tactical Goals influence each other inside the Tactical Layer.

Once the organization has established its competitive requirements to achieve success in business (Strategic Goals) and subsequently has devised particular ways (Tactical Goals) for implementing such requirements, it has to plan the implementation of such goals with the available company's capabilities by means of the concept of operation. This discussion is reflected in Figure 2 with the Tactical Goals connected to operations in the Operations Layer. 


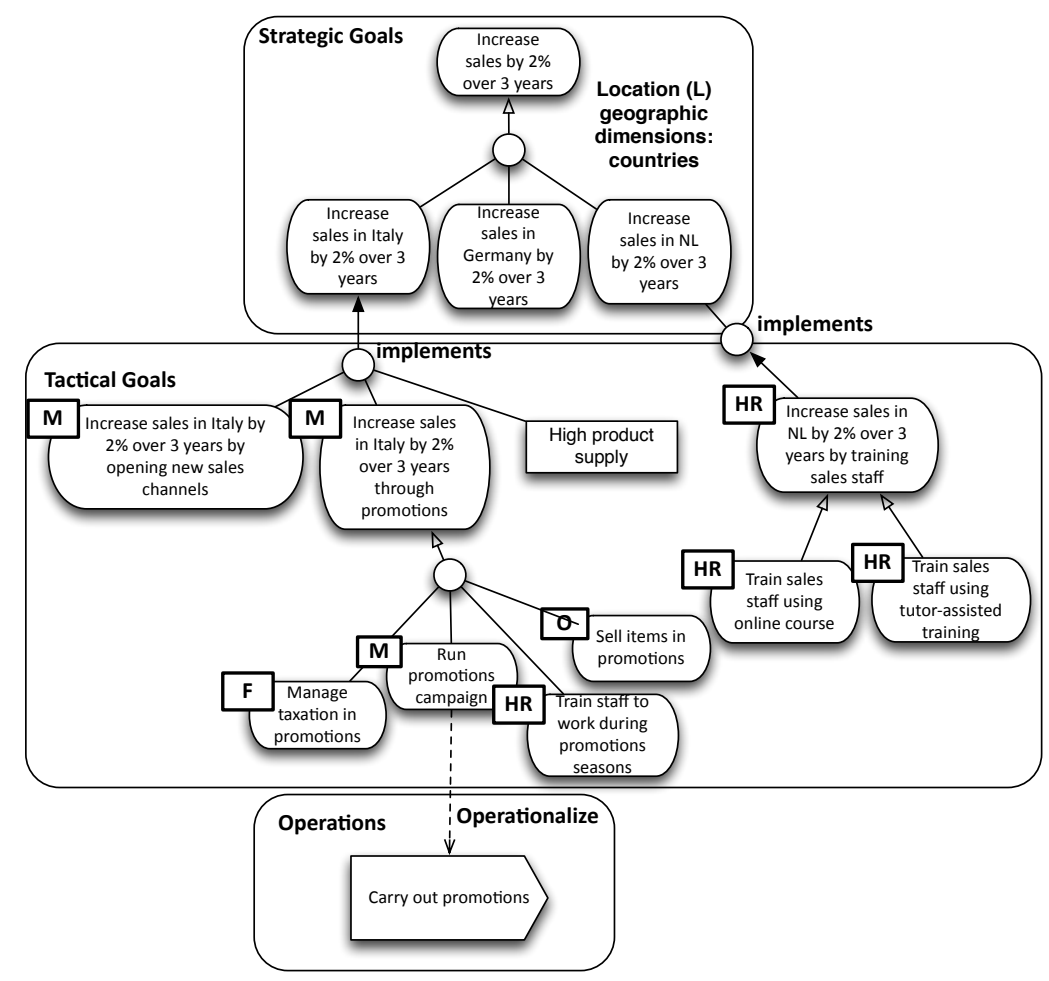

Fig. 2. Tactical Goal Hierarchy

Within the Operational Layer, as Management Sciences provides a simplistic treatment for the specification of operational goals, our framework starts with the same definition of this discipline and subsequently refines it:

Operational Goals. Operational goals correspond to the results that must be achieved in the course of performing the organization's operations. Our framework further details their definition by arguing that they represent a description of milestones the operation must reach in order to ensure that they are indeed planning the execution of tactics. Operational goals can be further refined with respect to the entities that are responsible for their achievement as follows:

(Operational) Role Goals. Correspond to goals that specify the results to be achieved by roles and individuals in the course of the performing their daily work. In Figure 3(b), "Choose items for promotion" and "Choose promotions price" consist of operational goals assigned to roles of the company.

(Operational) Business Process Goals. Correspond to goals that represent the final state to be achieved by a business process. The concept of Business Process is explained in Section 3.2. In Figure 3(b), "Advertise items in promotion" is a business process goal as it reflects the final state to be achieved by the "Advertise items in promotion" business process. 
Operational Goals may be related by AND/OR-relationships to represent refinements among them as well as Influence relationships (+/- contributions).

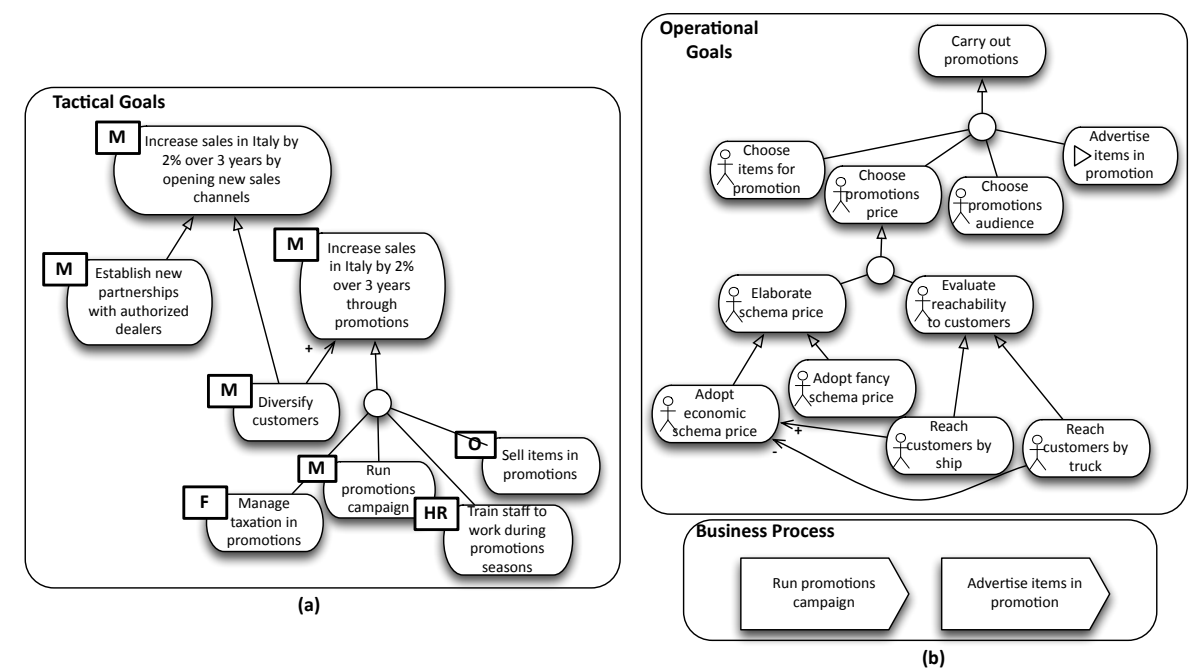

Fig. 3. Operational Goals and Business Processes Hierarchy

As one of the purposes of our modeling framework is to enable managers to adequately plan enterprise's goals and the corresponding operational elements that satisfy them, during the enterprise planning activity is important to foresee the potential future scenarios that facilitate or hinder the achievement of enterprise's goals (i.e., SWOT factors) together with assumptions about the environment. Therefore, our framework inheres the concepts of Situation and Domain Assumption from BIM framework. Situations are represented by triangles attached to goals by means of arrows annotated with the type of influence of situations on goals, whereas Domain Assumptions are represented by means of rectangles attached to goals. Figure 1 admits that a financial crisis may threat the achievement of the "Increase sales in Italy by $2 \%$ over 3 years" Strategic Goal. Further, for both tactics to work for this goal (new sales channel and promotions), analysts assume a high supply of products for Italy (Figure 2).

\subsection{Operations View}

While the concept of Operation is central within the Management literature as a process that transforms inputs into useful outputs, in our framework, we go further by distinguishing between Operation and Business Process:

Operation. Consists of a high-level process in charge of planning the execution of a specific tactics. A given operation encompass both what has to be achieved (Operational Goals) to concretize the tactics as well as how to conduct 
operational steps to achieve such tactics (business process). As operations plan the implementation of a given strategy, it is said that an operation operationalize Strategic or Tactical Goals in our framework, i.e., operations are solutions for Strategic/Tactical goals. Notice also that while operations may run independently, a given tactics is a plan of how to implement a particular strategy.

The concept of business process inheres the same definition of Operation from Management Sciences as follows:

Business Process. Consists of an activity conducted with the purpose of transforming a set of inputs into useful outputs (products or services) using some sort of transformation process. Differently from Operations, business processes intend to produce products or provide services to final customer.

To exemplify the concepts of Operation and Business Process, we use Figures 2 and 3. In Figure 2, one can see that the organization decided to either use promotions or open new sales channel as tactics for increasing sales in Italy and therefore, "Carry out promotions" is the Operation used to plan the execution of the promotion tactics. In its turn, the "Carry out promotions" Operation consists of collections of operational goals and business processes (depicted in Figure $3(\mathrm{~b})$ ). The operational goals specify certain milestones to be achieved during the planning of promotions, such as to choose how many promotions are required and decide what to offer in each promotion ("Choose items for promotion"), choose promotions price and audience ("Choose promotions price" and "Choose promotions audience") and advertise items in a promotion ("Advertise items in promotion'). Finally, "Run promotions campaign" and "Advertise items in promotion" business processes are the entities that are responsible for indeed executing the planning of the promotions and advertising the items in promotion.

\section{Methodological Guidelines for Goal-Driven Design of Operations Architecture}

This section provides methodological guidelines that prescribe how to elaborate, refine and operationalize goals by means of operations and business processes in our modeling framework. In order to prescribe such guidelines, as goals and operation planning occurs at formalized, step-by-step procedures in companies, we start by describing managers' concerns during goal and operations planning extracted from Strategic Planning literature. Subsequently, we explain how these concerns should be specified in our modeling framework. Although Strategic Planning literature mentions the existence of both a (top-down) deliberate and (bottom-up) emergent strategy formation process [15], we here focus on a traditional, top-down strategic planning for goal definition and implementation, leaving as future work the bottom-up strategy formation.

\subsection{Guideline G1: Elaborate Mission and Vision Statements}

At the Strategic Level, the first managers' step comprehends the articulation of organization's mission and vision as means of providing a general sense of direction for the company. 
Mission and Vision Elaboration. The guideline is to elaborate a mission statement that reflects the value the organization intends to deliver to the external world. For profit companies, given that organizations can be either manufacturing or service organizations $[18,13]$, value aggregation is performed by enumerating the products or services the company produces. For non-profit companies, the mission statement should capture other forms of value that provide social justification and legitimacy of the existence of the organization. For instance, Greenpeace's mission reflects this aggregation of value as “... Greenpeace's goal is to ensure the ability of the earth to nurture life in all its diversity..." [4]. The guideline for the elaboration of vision statements is to enumerate the products and services which are currently not implemented by the organization's, but there is an intention to address them on the company's portfolio.

\subsection{Guideline G2: Elaborate Strategic Requirements}

Strategic planning within the Strategic Level intends to guide the organization to achieve a successful position in a competitive environment, while achieving its goals [17].

Strategic Goals Elaboration. In order to compete, managers first identify external aspects that impact the ability of the organization to surpass its competitors. Following, internal aspects that enable the organization to gain competitive advantage such as capabilities, resources and competences are also evaluated. With such aspects in hands, the organization defines how it intends to compete and then elaborates its Strategic Goals. For instance, the Acer PC manufacturer [2, p.492] identified that Dell competes on the basis of low manufacturing costs. This could represent an external threat for Acer that may lead Dell to become the market leader in computers. Based on internal evaluation of its assets, Acer decided to gain competitive advantage based on management philosophy of highly motivated employers. Therefore, Acer elaborated the "Increase sales" Strategic Goal. With the elaboration of this Strategic Goal, Acer intended to become the market leader supported by an internal capability.

Strategic Goals Refinement Rules. Strategic Goals can be AND-refined by following structural domain rules or based on dimensional refinement. Refinement based on structural domain rules is applied when there exist a mathematical formula that relates domain variables and enables one to structurally decompose a goal into sub-goals using this formula. For example, once we know the profit stemmed from sales can be described by the formula salesProfit = numberSoldItems * profitMarginPerItem and managers intend to increase this profit ("Increase sales profit by $2 \%$ over 3 years" goal), one can increase volume sales (numberSoldItems) and maintain profit margin, yielding the following goals: "Increase volume sales by $2 \%$ over 3 years" and "Maintain gross margin by $2 \%$ over 3 years" (Figure 1). An alternative decomposition of the same root goal could also consider an increase in the profit margin, yielding "Maintain volume sales by $2 \%$ over 3 years" and "Increase gross margin by $2 \%$ over 3 years" as sub-goals. 
Dimensional refinement allows one to AND-decompose a goal with respect to a number of refinement dimensions introduced in Section 3.1. A dimension is introduced when a Strategic Goal has different operationalizations for different parts of the problem space. For example, there exist different solutions for increasing sales in Italy, Germany and NL ("Increase sales by $2 \%$ over 3 years" goal in Figure 1) and therefore, the location is an eligible refinement dimension. The following rules can be applied when using dimensional refinement: (i) time dimension: used when seasonal variations of business aspects (e.g., toys sales increase during Christmas season) may impose different operationalizations for the Strategic Goal; (ii) location dimension: used when the company presents a distributed organizational structure across distinct locations (e.g., sales departments for different countries) and the way in which the company pursue the Strategic Goal varies according to place under consideration; (iii) product, service, customer type dimensions: products, services and customers usually have a number of properties that characterize them (e.g., patients under 20 years old, different metal products, etc.) and operationalizations of the Strategic Goal varies according to the values that such properties may assume.

\subsection{Guideline G3: Elaborate Tactical Requirements and Operations}

Within the Tactical Level, the strategy is put into action by creating "tactics" that are particular ways for implementing the achievement of Strategic Goals with the deployment of organizational assets $[20,17]$.

Tactical Goals Elaboration and Implement-relationship. For the elaboration of Tactical Goals, "tactics" (particular solutions) must be found to implement each point of the refinement dimensions introduced during the Strategic Goals Refinement. This discussion has been exemplified in Section 3.1 with the "Increase sales by $2 \%$ over 3 years" Strategic Goal refined in terms of the location refinement dimension and implemented by offering promotions or opening new sales channel (in Italy) or alternatively, by training sales people in NL (depicted in Figure 2). Observe that Tactical Goals inhere the properties of parent goals that have been refined through dimensional refinement, i.e., the Tactical Goal "Increase sales in Italy by $2 \%$ over 3 years through promotions" inheres the same properties of the refinement across location from the "Increase sales in Italy by $2 \%$ over 3 years" Strategic Goal. Further, each leaf level Strategic Goal has to be implemented by one or more Tactical Goal, otherwise strategies will be not effective. Inversely, each Tactical Goal implements one and just one Strategic Goal to avoid confusions between tactics that implement different Strategic Goals.

Tactical Goals Refinement Rules. AND-refinement. After finding solutions for points of refinement dimensions (tactical refinement), managers must AND-refine such solutions across the responsibilities of each functional area of the company. For instance, in order to increase sales in Italy, offering promotions or opening sales channel correspond to two tactics that pertain to the responsibilities of the Marketing area. In its turn, other functional areas of the company have also responsibilities in the context of promotions. This is reflected in Figure 2 with the "Increase sales in Italy by $2 \%$ over 3 years through promotions" 
AND-refined into four distinct goals, each of them representing the responsibility of each functional area. Functional areas are represented in our model by attaching squares with their first letter to goals (see Figure 2). OR-refinement: a Tactical goal is OR-refined if there are different alternatives for achieving the same Tactical Goal. In our example, two alternative types of sales channels can be opened, i.e., by finding new partners to distribute the products or by finding new customers. Therefore, the "Increase sales in Italy by $2 \%$ over 3 years by opening new sales channels" is OR-refined into "Establish new partnerships with authorized dealers" or "Diversify customers" (Figure 3(a)).

Tactical Goal Operationalization and Operations Modeling. The refinement of Tactical Goals finishes when it is possible to plan and schedule the achievement of a Tactical Goal by assigning it an operation. In this case, it is said that an operation operationalizes a Tactical Goal which corresponds to the final state to be achieved by its corresponding operation. Tactical operations can be scheduled and executed with a certain frequency in order to achieve the Tactical Goal.

\subsection{Guideline G4: Elaborate Operational Requirements and Business Processes}

At the Operational Level, the execution of tactics is planned by planning the expected results from organization's daily operations [17]. In our framework, expected results are delivered by means of setting the Operational Goals together with the business processes that deliver such results.

Operational Goals Elaboration. As the Tactical Goal corresponds to the final state to be achieved by the operation that operationalizes such Tactical Goal, the elaboration of Operational Goals indeed starts by refining this Tactical Goal into intermediate milestones that compose its corresponding operation. These milestones are elaborated by specifying which results the operation must accomplish, regardless how this is accomplished. For the company's operations to be valuable, milestones must be elaborated considering that they need to add value to the final product. Therefore, these operational milestones are valueadding responsibilities (e.g., "Choose items for promotion" like the ones provided in Section 3.2).

Operational Goals Refinement Rules. AND-refinement. An ANDrefinement is used for structurally decompose a Tactical Goal (operationalized by a given operation) into intermediate Operational Goals (milestones) necessary for the execution of some tactics. An example of milestones refinement has been provided in Section 3.2. OR-refinement. An Operational goal is OR-refined if there are different alternatives for achieving the same Operational Goal.

Operational Goals Operationalization and Business Process Architecture Modeling. As Operational Goals may be achieved by either roles or business processes, the refinement of Operational Goals finishes when it is possible to find a business process whose final state corresponds to the Operational Goal under consideration. When a greater level of granularity should be con- 
sidered, the refinement may finish when it is possible to assign roles for the satisfaction of Operational Goals (Figure 3(b)).

Situation Modeling. As SWOT analysis intends to spot the conditions in company's environment that affect the achievement of its goals and the nature of this impact, analysts should spot the internal enterprise's conditions (strengths/weaknesses) and external (opportunities/threats) and represent them as situations and domain assumptions attached to goals. In particular, situations may be suitable for devising SWOT factors that affect the ability of the company to surpass competitors in the Strategic Layer. In the Tactical Layer, situations may be useful for reasoning about the applicability of certain tactics in certain specific contexts. In Figure 1, one can see the "high demand in automotive industry" as an opportunity for increasing sales in Germany and the "low availability of steel in the market" as a threat for increasing the sales in the 3rd year.

\section{Related Work}

Goal and operations modeling have a long trajectory in a number of areas of computer science, such as Enterprise Modeling (EM) and Business Process Management (BPM), among others. Enterprise modeling frameworks inherited the GORE idea that goals can be used as the driving principle for the generation of the enterprise architectures. In this context, the ArchiMate Motivational Extension (AME) extends the core ArchiMate enterprise framework by introducing common GORE concepts like (soft)goals, AND/OR refinements and contribution relations among goals and requirements. Goals are connected to other concepts of ArchiMate by means of a realization relation with services and business processes. In [1], similarly to our approach, authors analyze strategic planning literature to extend AME with finer grained concepts such as mission, vision, precedence among goals, time interval for goal achievement, responsibility and delegation among goals. However, the extension solely focuses on strategic concerns, thus not presenting a layered structure like our approach.

Similarly to our approach, other frameworks in enterprise modeling, such as the EKD [8], ARIS [16] and i* [21,11] also consider the generation of a set of business processes having goals as a starting point. Although the generation of the architecture of process from goals is a similar feature to our approach, proposals either focus on the representation of strategic or operational goals, do not taking an integrated approach to link the whole hierarchy of enterprise goals to the architecture of operations.

A large body of knowledge in BPM has also explored the interconnection between goals and operations (or business processes), by relating goals with the internal logics of the process $[10,14,12,9]$. We consider our approach to advance the representation features of this group of approaches as we distinguish among

distinct types of goals and operations, while such approaches sole focus on the representation of our concept of operational goals. 


\section{Conclusions and Future Work}

In this paper, we have proposed the Strategic Enterprise Process Architecture (SEPA) modeling framework that extends BIM and BMM by including different shades of goals and operations extracted from Management literature. In particular, we provide clear-cut definitions for goals and operations and also include methodological guidelines on how to build enterprise process architecture models. Regarding evaluation of our modeling framework, we are currently working on the evaluation of our proposal by means of a real-world case study in a hospital setting. Further, although we are not able to depict our full hierarchy of strategic enterprise models due to space constraints, we make it available at: https://www.dropbox.com/s/azvehs3eabugpzc/Full.

As a future work, we envision three natural directions for refinement of our modeling framework. The first direction concerns the representation of detailed consumer-producer and triggering relationships among operations and business processes. Second, a reasoning approach that generates alternative set of operations/business processes (enterprise process architecture) on the basis of the goal hierarchy should also be considered. Finally, although the goal structure is richly grounded on key distinctions of Management literature, we refrain from addressing how the execution of operations and processes entails the achievement of strategic goals. This is certainly an important step to be tackled by our methodology.

Acknowledgments. We would like to thank Jennifer Horkoff for her useful comments in the research reported in this paper. This work has been partially funded by the Spanish Ministry of Economy and Competitiveness (MINECO/FEDER) under the Granted Project SEQUOIA-UA (Management requirements and methodology for Big Data analytics) (TIN2015-63502-C3-3-R).

\section{References}

1. Azevedo, C., Almeida, J., van Sinderen, M., Ferreira Pires, L.: Towards capturing strategic planning in ea. In: IEEE 19th International Enterprise Distributed Object Computing Conference (EDOC2015). pp. 159-168 (2015)

2. Daft, R., Samson, D.: Fundamentals of Management: Asia Pacific Edition. Cengage Learning (2014)

3. DuBrin, A.: Essentials of Management. Cengage Learning (2011)

4. Greenpeace.org: Greenpeace Core values, url = http://www.greenpeace.org/international/en/about/our-core-values/, urldate $=2016-07-11$

5. Group, O.M.: Business Motivation Model - Version 1.0. Object Management Group (OMG) (2015)

6. Horkoff, J., Barone, D., Jiang, L., Yu, E., Amyot, D., Borgida, A., Mylopoulos, J.: Strategic business modeling: Representation and reasoning. Software \& Systems Modeling 13(3), 1015-1041 (2014)

7. Joyce, P., Woods, A.: Strategic Management: A Fresh Approach to Developing Skills, Knowledge and Creativity. Kogan Page (2001) 
8. Kavakli, V., Loucopoulos, P.: Goal-driven business process analysis application in electricity deregulation. In: Advanced Information Systems Engineering, vol. 1413, pp. 305-324. Springer Berlin (1998)

9. Koliadis, G., Ghose, A.: Relating Business Process Models to Goal-Oriented Requirements Models in KAOS, pp. 25-39. Springer Berlin (2006)

10. Korherr, B., List, B.: Extending the EPC and the BPMN with business process goals and performance measures. In: 9th International Conference on Enterprise Information Systems (ICEIS2007). pp. 287-294 (2007)

11. Lapouchnian, A., Yu, E., Sturm, A.: Re-designing process architectures towards a framework of design dimensions. In: IEEE 9th International Conference on Research Challenges in Information Science (RCIS2015). pp. 205-210 (2015)

12. Lapouchnian, A., Yu, Y., Mylopoulos, J.: Requirements-driven design and configuration management of business processes. In: Business Process Management, vol. 4714, pp. 246-261. Springer Berlin (2007)

13. Mahadevan, B.: Operations Management: Theory and Practice. Pearson (2010)

14. Markovic, I., Kowalkiewicz, M.: Linking business goals to process models in semantic business process modeling. In: IEEE 12th International Enterprise Distributed Object Computing Conference (EDOC2008). pp. 332-338 (2008)

15. Mintzberg, H., Ahlstrand, B., Lampel, J.: Strategy safari: A guided tour through the wilds of strategic management (2005)

16. Neiger, D., Churilov, L.: Goal-oriented business process modeling with epcs and value-focused thinking. In: Business Process Management, vol. 3080, pp. 98-115. Springer Berlin (2004)

17. Plunkett, W., Attner, R., Allen, G.: Management: Meeting and Exceeding Customer Expectations. Cengage Learning (2007)

18. Reid, R., Sanders, N.: Operations Management: An Integrated Approach. Wiley (2005)

19. Saloner, G., Shepard, A., Podolny, J.: Strategic Management. John Wiley (2001)

20. Srivastava, R., Verma, S.: Strategic Management: Concepts, Skills and Practices. PHI Learning (2012)

21. Yu, E., Mylopoulos, J.: Using goals, rules, and methods to support reasoning in business process reengineering. In: System Sciences, 1994. Proceedings of the Twenty-Seventh Hawaii International Conference on. vol. 4, pp. 234-243 (Jan 1994) 